\title{
MARKET FAMILIARITY AND EXPORT SURVIVAL: WHEN EXPERIENCE MAKES EXPORTING MORE DYNAMIC
}

\author{
ELIANE CHOQUETTE \\ Department of Management \\ Aarhus University \\ Aarhus 8210, Denmark
}

\section{INTRODUCTION}

Understanding the determinants behind the performance of firms in international markets has been the focus of a vast amount of research in the international business literature (Sousa, Martínez-López, \& Coelho, 2008), with a majority of studies offering explanations to firms' export intensity, growth, and profitability (Sousa, 2004). Recently, a growing interest in the survival of export activities (or put differently firms' decision to exit export markets) emerged (Bernini, Du, \& Love, 2016; Sui \& Baum, 2014). This growing interest coincides with empirical evidence documenting that, despite the costs involved in entering new export markets, a large share of newly established export relationships fail shortly after they begin (Besedes \& Prusa, 2006). These findings suggest that a large proportion of firms face challenges in sustaining their activities in international markets and that research furthering our understanding of what drives the continuity of export relationships is therefore needed. A greater understanding of what ensures survival in export markets is relevant for businesses and politicians alike as it has been shown that the major part of a country's export growth comes from expanding existing export relationships rather than establishing new ones (Besedeš \& Prusa, 2011). Yet, only a deeper understanding of the drivers behind the decision to exit export markets will enable us to conclude whether export market survival is a sign of superior performance and should in itself be an endgoal.

The existing literature on the determinants of export survival has identified a list of variables at the country, firm, and product level, which are associated with the probability of firms ceasing their export activities in particular markets and/or of particular products. Among them, firms' international experience has received significant attention within the export survival literature. Most research reveals a positive relationship between international experience and firms' export survival (Carrère \& Strauss-Kahn, 2017; Stirbat, Record, \& Nghardsaysone, 2015). While previous research has conceptualized firms' international experience in different ways, it has been common to focus on the outward internationalization of firms, such as export experience. Complementary to this perspective, this paper focuses on the role of market familiarity coming from import-based market experience in explaining firms' survival in individual export markets. By doing so, this paper acknowledges that firms' initial encounters with a foreign market may not always be via exporting and consequently firms may become familiar with a foreign market prior to initiating exports (Welch \& Luostarinen, 1993). This dimension of firms' international experience has been largely overlooked in the literature, particularly in the context of export survival.

\section{THEORETICAL BACKGROUND AND HYPOTHESES}


This paper argues that, from a theoretical perspective, being familiar with a foreign market prior to export market entry has a two-sided effect on a firm's survival in export markets. Under the assumption that firms gain knowledge about a market through import-based market experience, this paper contends that the response of decision makers to this increased market knowledge is not as straightforward as often assumed in the literature.

On the one hand, from a learning perspective, we would expect a positive relationship between international experience and export survival. The significant uncertainty surrounding the decision to start exporting to new markets implies that firms are unable to precisely estimate the profitability of entering an export market before actually doing so (Albornoz, Pardo, Corcos, \& Ornelas, 2012; Nguyen, 2012). Because of this uncertainty, firms start exporting to individual markets without fully knowing how lucrative this endeavor will turn out to be. Some firms will then cease export activities once they "discover" their profitability in the new market. As such, factors reducing the uncertainty surrounding the profitability of starting to export to a market should lead to higher survival odds in export markets due to better-informed decision making related to the choice of export markets to serve (Carrère \& Strauss-Kahn, 2017). Existing research has argued and shown that the knowledge gained from prior international experience is a credible way for firms to reduce this uncertainty (Carrère \& Strauss-Kahn, 2017; Stirbat et al., 2015). Based on that, the first hypothesis sustains that:

\section{Hypothesis 1: Firms are less likely to exit export markets in which they had import experience prior to export market entry.}

On the other hand, economists have explained the persistence of firms' export involvement by the presence of sunk costs associated with entering a new export market (Roberts $\&$ Tybout, 1997). The argument behind this explanation is that, because of the uncertainty about the future profitability of a foreign market and to avoid having to repay sunk entry costs in the future, firms will not immediately reverse their decision to export even though conditions within a market become less favorable (Dixit, 1989). Previous evidence suggests that the knowledge gained through prior import experience reduces these sunk costs (Bas \& Strauss-Kahn, 2014; Meinen, 2015) and therefore import-based market experience should influence firms' survival in export markets. The sunk cost logic suggests that firms facing lower sunk costs would react more quickly to (unfavorably) changing market conditions. As such, firms who faced lower sunk costs are more likely to be the first ones to exit an export market with declining demand conditions. Moreover, because of these lower sunk costs, firms may exhibit a higher propensity to experiment with internationalization ( $\mathrm{Li}, \mathrm{Yi}, \&$ Cui, 2017), ultimately leading some inept firms to enter export markets. One would expect these inept exporters to exit shortly after entry. Thus, and contrary to the learning argument, the second hypothesis of this paper sustains that:

\section{Hypothesis 2: Firms are more likely to exit export markets in which they had import experience prior to export market entry.}

Which of these two logics dominates is unclear from a theoretical point of view and ultimately depends on the relative importance of one effect over the other. This warrants further research exploring the boundary conditions of the experience-export survival relationship. As a first step in that direction, this paper proposes to focus on the similarity between the domestic and the export market as an important moderating variable. This paper argues that market 
similarity relates to the level of sunk costs associated with exporting, where markets that are more dissimilar require larger sunk investments prior to export market entry. As the expected profitability threshold at which a firm decides to exit a market decreases non-linearly with the level of sunk costs (Dixit, 1989), a reduction in those costs as a result of prior experience is expected to lead to even quicker responses to changing market conditions in cases where the export market is more similar. Moreover, the higher level of sunk costs associated with entering dissimilar markets, in spite of prior experience, may prohibit some of the experimentation-like responses to increased knowledge, resulting in fewer exits. Accordingly, the third hypothesis of this paper sustains that:

Hypothesis 3a: Market familiarity prior to export market entry increases the probability of a firm exiting export markets that are relatively similar to the home country.

Hypothesis 3b: Market familiarity prior to export market entry decreases the probability of a firm exiting an export markets that are relatively different from the home country.

\section{METHOD}

The aforementioned hypotheses are tested on a sample of 16,541 export market entries (i.e. spells) made between 2001 and 2011 by 2,007 manufacturing firms located in Denmark. Detailed data on the import/ export history of these firms are used to estimate their probability if exiting individual export markets, based on the experience they had at entry - among other factors. As the focus of this paper is on assessing whether market familiarity affects the survival/exit of firms on individual export markets, the analysis is done using a duration model set-up. Because the data used in this paper are reported on a yearly basis, a discrete-time proportional hazard model (cloglog) is used as the baseline model to estimate the factors influencing the failure rate of firms in export markets.

\section{Dependent Variable}

To estimate the probability of firm i surviving in export market $j$, we need to create a dummy variable depicting whether a firm discontinues its export activity to market $\mathrm{j}$ in year $\mathrm{t}$. This dichotomous variable takes the value 0 from the first year for which a positive export value is registered until the last year we observe positive export sales, in which case it takes the value 1 .

\section{Independent Variable}

To test the hypotheses developed in this paper, a dichotomous variable capturing firms' market familiarity prior to export market entry has been constructed using the history of a firm's import activities. The variable is equal to one if firm $i$ is importing from market $j$ in the year prior to starting to export that same market $j$. This variable remains constant over time for each firm-destination pair. 


\section{Control Variables}

In line with previous literature, labor productivity (Bernard \& Jensen, 2004), firm size (Bernini et al., 2016; Sui \& Baum, 2014), firms' average hourly wage (Bernard \& Jensen, 2004), international experience - both general and within a region (Albornoz et al., 2016; Stirbat et al., 2015), current market-specific import status, and the initial level of sales in the foreign market are controlled for. Moreover, destination, industry, and year dummies are included to control for unobserved heterogeneity across destinations and sectors as well as time trends.

\section{RESULTS}

\section{Market Familiarity and Export Survival - H1 and H2}

The results of the main estimation shows that market familiarity gained through imports prior to export market entry increases the probability of a firm to exit an export market by roughly 38 percent. This effect is both statistically and economically significant and suggests that the sunk costs logic dominates the learning effects (lending support to $\mathrm{H} 2$ ).

As previously advanced, one reason why firms that are familiar with a foreign market at the time of entry are more likely to exit the export market is rooted in experimentation. Indeed, firms face lower entry sunk costs in markets with which they are a priori familiar, leading them to undertake less carefully analyzed entries, in turn resulting in higher chance of exit. In an attempt to shed light on whether this is a valid explanation, a probit model estimating the probability of a firm to be a sporadic exporter (defined as exporting to a market for one year only) is used. The results show that firms that are familiar with a foreign market at entry are indeed more likely to be sporadic exporters. This indicates that some experimentation may indeed be taking place.

Moreover, another explanation behind the main result of this study is rooted in the sunk cost logic which predicts that, all else equal, firms facing lower sunk entry costs will have a narrower band of inaction in the face of changing market conditions. This narrower band of inaction implies that familiar firms will be more likely to react to less favorable market conditions. To test if this explanation holds in the present context, equation (1) is estimated on a sub-sample of unfavorable destinations (proxied by a null or negative yearly GDP growth). The results are in line with the reasoning presented above, and show that firms that are familiar with a foreign market at entry are more likely to exit markets when facing negative growth. This suggests that familiar firms indeed are less tolerant towards unfavorable market conditions, compared to non-familiar firms.

\section{Market Familiarity and Export Survival - H3a and H3b}

Estimations for the sub-sample of EU15 countries, other High-Income destinations (HIC), and Low-Income destinations (LIC) show that the sunk cost logic dominates in most types of markets. Yet, the magnitude of the effect is considerably smaller for less similar destinations. Indeed, in the sub-sample of EU15 destinations, firms exhibit a double as large probability of exiting a market if they were initially familiar with it. For other High-Income countries, the effect is reduced to 21 percent, while for Low-Income destinations the effect is insignificant. Hence, while the learning effects do not appear to dominate in dissimilar markets 
(as it was expected), the results suggest that the relative impact of learning is larger in such markets, despite not being large enough to compensate. As such, the results lend support to H3a but not $\mathrm{H} 3 \mathrm{~b}$.

\section{DISCUSSION}

The findings of this study contribute to the literature on export market survival in three ways. First, it explores the effect of a generally overlooked source of knowledge available to firms when internationalizing through exports, namely import-based market experience, while also controlling for firms' export experience. As such, this study complements the existing literature by showing that import-based market experience is a determinant of firms' survival in export markets. The distinction between different sources of experience turns out to be important; the results suggest that the effect of import-based market experience is opposite to that of export-based experience.

Second, this paper conceptually contrasts and empirically tests two opposing views on the effect of prior market-specific experience (gained through imports) on the survival of export relationships. The findings testify to the importance of paying closer attention to the possible implications that knowledge may have on decision-making, showing that more knowledge about a foreign market may trigger less cautious decisions and experimentation-like export behavior.

Third, the paper provides insights into the conditions under which knowledge gained from import-based experience may lead to positive and/or negative effects on export market survival.

\section{CONCLUSION}

This paper investigates the effect of market familiarity at export market entry on the subsequent survival of firms in individual export markets. Applying diverse theoretical lenses, competing hypotheses on the relationship between market familiarity and export market survival are developed and tested. Moreover, this paper hypothesizes that the effect of market familiarity on export survival depends on the initial level of sunk costs associated with entering a particular export market. The findings show that a sunk cost logic dominates learning effects associated with market familiarity, and does so in all types of export markets.

\section{REFERENCES AVAILABLE FROM THE AUTHORS}

